\title{
KNOWLEDGE FOR INTELLIGENCE: DISCUSSING THE STATE AND THE ROLE OF BUILDING DATA IN ITALY
}

\author{
A. Pasquinelli ${ }^{\text {a*}}$, F. Guzzetti ${ }^{\text {a }}$ \\ a ABC Dept., Politecnico di Milano, Via Ponzio 31, 20133 Milano (alice.pasquinelli, franco.guzzetti)@polimi.it
}

KEY WORDS: Smart Asset Management, Building Data, Data Integration

\begin{abstract}
:
The availability of integrated information on buildings is the premise for an effective assets management and the provision of innovative services to buildings users: such form of knowledge relies on the efficient exploitation of existing data, providing a complete overview on the state of buildings, and on the acquisition of real-time data flows, coming from sensor and mobile devices, reporting users behaviours. If, on the one hand, technology is progressively enabling the management of new huge streams of data, on the other hand the interconnection among traditional and well rooted datasets, the majority of which in charge of public administrations, is not always guaranteed. While, at European level, interoperability issues among public archives concerning buildings were properly addressed, and the relevance of geo-information is widely recognized, in Italy this process is still taking time to be undertaken. This paper discuss the current state of Building Information in Italy, outlining a possible path for the creation of a georeferenced Building Information System at municipal level, starting from the informative heritage available in existing databases, generated with different purposes and maintained by independent authorities: the idea is to solicit that digitalization process, started a decade ago with the "Digital Administration Code", through the proposition of real use cases that might be implemented once that public data on buildings are profitably combined together.
\end{abstract}

\section{INTRODUCTION}

New challenges related to population growth and human concentration in urbanized areas are currently soliciting governments and policy makers in the development of smart management models able to deal with increasingly complex cities. As stated in a recent United Nation report (UN-GGIM, 2015) "the integration of smart technologies and efficient governance models will increase and the mantra of 'doing more for less' will be more relevant than ever before”. From this point of view, the availability of data on urban features and environments is a basic premise for the definition of policies and management models that will ensure the provision of more efficient services and the reduction of human impacts on natural environment and resources.

The management of the built environment, and buildings in particular, is a strategic issue: buildings are places dedicated to the hosting of a growing urban population and are the key for the provision of efficient services to new citizens (AGI, 2015). Moreover the definition of strategies aimed to improve the quality of buildings and their energy efficiency play a critical role in the reduction of GHG emissions: the Energy Performance of Building Directive 2010/31/EU recast states that buildings account for $40 \%$ of total energy consumption in the European Union and a shift toward a reduction in energy needs and new renewable sources would reduce the carbon footprint caused by the building sector. Efficient building management and renovation strategies requires data on the existing building stock able to orient available resources in a systemic way: as claimed by the report of the International Energy Agency on Energy Efficient Communities, in place of developing measures on single cases, boosting the renovation at district level could be more effective and viable (IEA-EBC,
2013). Thus, the availability of data on buildings at city or district scale is crucial for the effective management of the city of tomorrow.

At European level, a general framework on building geoinformation is provided by the INSPIRE directive (Directive 2007/2/EC): the scope of this initiative is to provide common rules for the realization of geographic datasets on natural and built environment, in order to realize a European database supporting the implementation and the monitoring of the effects of environmental policies, especially in cross-border areas. The use of spatial information for the modelling of building information is addressed by the INSPIRE Data Specification on Building, that recognizes and adopts the international standard for City Modelling CityGML (INSPIRE, 2013) (OGC, 2012). But in order to realize a complete city model (or for the modelling of a specific theme) both geometric and semantic data coming from different data sources have to be combined together: thus the creation of city models relies on the availability and interoperability of data.

Many data on buildings exists nowadays, generally produced and maintained by public authorities in order to accomplish their ordinary duties (e.g. cadastral data, created for fiscal purposes): nevertheless, problems are associated with poor data quality, lack of updates and lack of interoperability between different data sources (UN-GGIM, 2015). Some European countries, as reported in section 2, started to work on data interoperability and integration issues several years ago, assuming them as a main concern at national level: in these contexts the gathering of existing data ensure an efficient management of available information, avoiding redundancies and improving data quality and the connection with georeferenced bases enabled the creation of City Models with

\footnotetext{
* Corresponding author
} 
different level of detail (Kruger and Kolbe, 2012) (Stzalka et al., 2010) (Nouvel et al., 2014).

In Italy, a digitization process of public archive has started in 2005 with the introduction of the "Digital Administration Code" but few initiatives were taken in order to relate existing data and to create a system of knowledge starting from them. In 2011 the Topographic Database (TDB), the new usage-oriented earth surface model, was introduced: the production of TDBs is currently in progress and is generally in charge of municipalities through the financial support coming from Regions. Despite its potential as a $2.5 \mathrm{D}$ geographic dataset, with the possibility to derive 3D building contents, the creation of relations between the TDB and other public archives is not considered by the current national Data Specification.

This paper starts from the current state of buildings information in Italy, outlining a possible path for the creation of an information system on buildings at municipal level starting from a georeferenced base. The proposed analysis is part of a research carried out for an association of mountain municipalities in Brescia province (Lombardy region): these municipalities are grouped as a Mountain Community, a particular type of administrative aggregation aimed to sustain small mountain settlements in the provision of services. The intent of this work is dual: firstly to demonstrate how, even if a national strategy on public data harmonization is missing, a bottom up process might be implemented enabling municipalities to create a local Building Information System; secondly, considering current data specification on the building theme provided within the INSPIRE directive framework, to align the quality of Italian building geo-data to European requirements.

\section{FOREIGN EXPERIENCES IN BUILDING DATA INTEGRATION AND HARMONIZATION}

\subsection{The Netherlands}

Since the beginning of ' 90 s the Netherlands undertook a process aimed to ensure a better management of data contained in public registries, creating connections between the main public datasets: a Key Registers system was created, hosting data considered essential for the public sector (Bakker, 2011). The scope of such initiative was to define a set of authentic information for data sharing, avoiding data duplication within governmental bodies (Van Der Molen, 2002).

The creation of this system started in late 1990s, comprising data with both geographical and non-geographical (administrative) nature. Basic principles were:

- Data share: data created afnd maintained at the source, but made accessible for other governmental institution and to the public. This allow to solve many criticalities related to the existence of many similar databases, like redundancy or incoherence among information, providing an efficient mechanism for data update and ensuring interoperability;

- Data as authentic and reliable for the users: contents of Key Registers are reference for all governmental bodies and their authenticity works as a guarantee for external users.

By establishing a set of key registers, the government intended to improve services, reduce administrative burden, and organize its own operational processes more efficiently. This approach made possible to gather data once, and to make it accessible by multiple users within the government. 13 are the Key Registers identified by the Dutch government and the Land Registry and Mapping Agency (Kadaster) is responsible for maintaining the spatial datasets.

Two aspects are relevant in this experience: on the one hand, the idea of an integrated information for an efficient government and the provision of authentic information; on the other hand, the role of harmonized geographic information connected with several other datasets. These two aspects contributed in turning information into services that Kadaster provides to private customers for the pursuit of their business: real estate agencies, for instance, not only have information on the single assets (plot or buildings), but can provide further details that are obtained through the interaction with other databases (what is the building potential of a plot? how many schools are available the surroundings?). Kadaster as an organisation became national center for geo-information services, rather than a pure cadastral agency as the name implies (De Zeeuw And Salzmann, 2011).

\subsection{Germany}

In his paper titled “ALKIS - Germany's way into a cadastre for the 21st Century” Hawerk (2001) outlined the strategy that the German Cadaster identified at the beginning of years 2000 for the transformation of the Land Registry in an Integrated Official Cadastral Information System (ALKIS). The reasons for such evolution was the need to avoid inefficient work flows related to the cadastral registries. Two are the main components of the German cadaster: the Automated Cadastral Map (ALK), providing a geometric description of properties, and the Automated Property Register (ALB), the descriptive part of the real estate. The two databases, initially developed as independent software solutions without mutual object structures, were lately harmonized and unified under the ALKIS system.

Not only: the creation of such unique cadastral system was connected with a redesign of the official Topographic Information System. The Authorative TopographicCartographic Information System (ATKIS) is a nationally standardized project that involved all Federal States in the realisation of a topographic database provided in the form of usage-oriented digital Earth surface models. Thus ATKIS is the public geo-topographic spatial reference basis for connection and linking with other geo-thematic technical data. ALK, ALB and ATKIS did not have the same object structures, impeding a straight data exchange among them: nevertheless the three turned out to be the most important basic data for GIS in Germany, used for a wide range of applications in the private and public sector.

Increasing demands from the real estate market, banks, navigation companies etc. put a high pressure on the authorities in charge to establish a National Spatial Data Infrastructure based on these data. Modern developments in object-oriented data bases, international standards and computer technology allowed Germany to invest in the development of a new integrated data base model for cadaster and topography, free of redundant data: the object catalogues and data of ALKIS and ATKIS were so conceived in order to have a matching data model, allowing a vertical data flow that avoid data redundancy and double work in data acquisition and data processing.

The cadastral data system and the topographic data system are nowadays two core geodatabases uniformly available in all 
federal states structured following a unique data model that comprises also geodetic references provided by the AFIS system (control points, GPS stations). This system is now in use since 2007 and provides an important base for the development for the current city-models, which can count on an easy communication among the two systems in order to put together topographic and semantic information.

\subsection{United Kingdom}

Ordnance Survey (OS) is the national mapping agency of Great Britain and the government department responsible for the official surveying and topographic mapping of Great Britain. It provides topographic and geographic data to the public sector through the Public Sector Mapping Agreement and help authorities developing applications for an efficient accomplishment of their duties and an effective provision of services.

Ordnance Survey, as a central mapping agency, focuses on the production of GIS data which are provided as base geographic data to public authorities that, in turn, realize other datasets that are geographically aligned with the OS ones: Environment Agency, for example, produce flood maps which are published and made available as interoperable with other OS geographic layers. This enable authorities involved in risk management to identify assets (buildings, lands, people) which are exposed to flood risks, set up proper emergency planning and develop emergency responding tools (e.g. flood alert applications). Moreover, as each property in Land Registry is connected to a OS spatialized address through a Unique Property Reference Number (UNPR), Land Registry can provide a Flood Risk Indicator for each real estate registered.

Data produced by OS are so a reference for all public administrations and are continuously updated and maintained centrally by the agency. OS and its partners also provides technical support for the development of tools and applications that allow a more efficient provision of services to citizens and, at the same time a more intelligent use of available resources. This means that, apart from the production of digital data, a real digital evolution in public sector were carried out.

Apart from the public sector OS geo databases are also sold to private actors for business purposes. Geographic data support banks and insurance companies for the reduction of risks connected to properties in the evaluation of the exposure to environmental hazard and in the reduction of frauds. Also, retail brands take advantage from location based services providing insights into new and existing stores as well as customers and competitors, considering also connection with roads and transport lines, easing the identification of optimal location for new store openings.

\subsection{Key points}

The analysis provided on foreign experiences revealed the potential deriving from an aggregated information on buildings: cited studies and experiences demonstrate how, even if requiring a significant effort in terms of data and procedures harmonization, it is possible to make the most value out of data, both in terms of increased efficiency in administrative duties and in the provisions of new services, to the public and to the private sectors.

Three key aspects are relevant when addressing data interoperability issues:
- The role of geo-information: spatial references are essential in the management of built environment considering that each built asset has a specific position on earth. The availability of georeferenced information enables the interrelation between different datasets sharing a common reference: the position, which do no to change over time;

- Efficiency in public data management: shared management mechanisms make data updates more effective, avoiding copies and incoherencies between databases and easing the management of a growing informative heritage;

- Data harmonisation: the semantic and geometric alignment between data is a time-consuming activity. Nevertheless it is the premise for the full exploitation of aggregated data on the built environment.

The provision of good quality, certified data represent not only an important aspect from an efficiency point of view but is also an added value that can be spent outside the public sector, ensuring a constant financing of public archive updates and maintenance.

Nevertheless each country has its own story and deals with its own legacies and background. For what concerns the management of built environment, information about buildings in Italy is fragmented across many sectorial databases which, however, are not related one to each other: even though many data are available nowadays, an aggregated information providing an exhaustive description of a building in all its features cannot yet be provided automatically.

\section{BUILDING INFORMATION IN ITALY}

In this section, three main sources of data on buildings are presented: the Topographic Database, the new format for local and regional cartographies which can provide a highly detailed, georeferenced base for the creation of a local Building Information System; the cadaster, centrally managed by the National Tax Agency ("Agenzia delle Entrate”), the historic database containing detailed information on real estates; census data on buildings, normally generalized and made available at census unit level, but which are originally collected (and made available for public administration only) at building level. The alignment between these three data sources would enable the connection with other existing databases (like Energy Performance Certificates database, Thermal Plants databases, energy consumption data...), and the geo-referenced base will ease the connection with real-time users data coming from sensors that might be installed on the buildings and with mobile devices.

\subsection{The Topographic Database}

New cartographies in Topographic Database (TDB) format provide a $2.5 \mathrm{D}$, thematically organized representation of the real world, associating self-consistent geometries with attributes describing the main features of the built and natural environment: the production of these cartographies, introduced at national level in 2011, is still in progress and is generally in charge of municipalities through the financial support coming from Regions. Topographic layers provide a geometric and semantic description of real world objects. All items recognizable in the built and natural environment are classified in themes and classes following a specific nomenclature: national data specifications on TDBs were released by the Italian Topographic Database Working Group within the framework of the so called "State-Regions-Local 
Administration Agreement on Geographic Information Systems" -INTESA GIS- (INTESA GIS, 2008). As a relational database, classes relates one to the others basing on topological and consistency constraints.

For what concerns the built environment, buildings in the TDB are defined as a set of volumes outside and underground composing a unique construction: this construction has a specific building typology, hosts one or more functions, has a certain level of maintenance. Buildings are so defined by building parts (volumes) combined together basing on common features (e.g. the building typology). As a consequence, buildings data concern:

- Building parts: providing mainly a metrical depiction of buildings in 3D. Key attributes for this layer are "vertical height"; "type of volume" (on the ground, portico, overlapped volume...); "building ID" (all volumes composing the same building share the same identifier);

- Buildings: obtained through geometrical generalization of all building parts referring to the same construction. Key attributes are "building ID”, "building typology”; “function”; "level of maintenance"; with the exception of the building identifier, values for the mentioned attributes are listed and enumerated by the data specifications.

The geometric accuracy depends on the cartographic scale adopted: the scale normally ranges between 1:1000 and 1:2000 in urbanized areas where most of the buildings are concentrated and the latter is the most common map scale adopted. In non- urbanized territories accuracy ranges between 1:5000 and $1: 10000$. It is important to highlight that data on roofs is generally missing: due to the high cost of the survey and editing of roof shapes, the provision of this type of information is hardly ever required (and financed) by the Regional administration. Geographic coordinates are expressed using the current National Geodetic Reference System ETRF2000.

TDB do not integrate data coming from other data sources. Conceived mainly as a cartographic product, obtained through aerial imagery, contents are related to what is visible and recognizable in stereo-pairs images: no information are provided on non-visible part of the buildings, like number of dwellings, floors below the ground, age of construction, etc. Also the current data structure do not require the connection with external data sources to be implemented, neglecting the possibility to retrieve these type of information elsewhere. If, on the one hand, highly detailed geometric data will be soon available for every municipality in Italy, on the other hand semantics will be limited only to few general information generated during the cartographic production phase.

The connection with external databases is the key for the inclusion of other relevant information on buildings: this is also a requisite for INSPIRE Data Specification on the building theme, that suggests to associate geographic building data with external references, especially cadastral identifiers (INSPIRE, 2013).

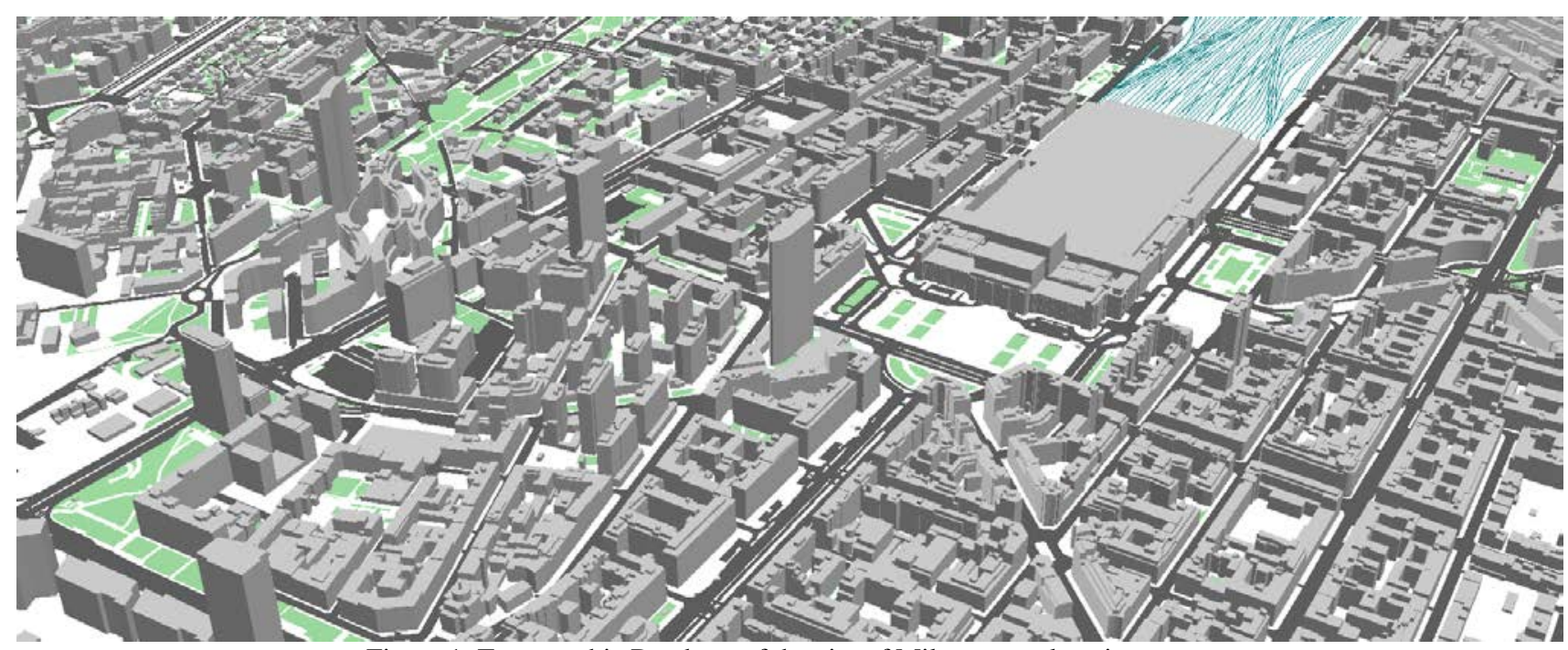

Figure 1. Topographic Database of the city of Milan: central station area

\subsection{Cadastral data}

The Land Registry is the national digital database on buildings "par excellence": in fact, it is currently the only database on buildings which is formally and homogenously available all over the county. Cadastral registers, created for fiscal purposes, host information describing the features of each real estate in order to determine the amount of taxes that owners have to remit. Italian cadaster provides three types of information:

- Geographic information: the cadastral map identify parcels, buildings, roads and water bodies;

- Geometric information: blueprints referred to each single Real Estate Unit within buildings;

- Descriptive information: the Cadastral Census Table ("Tavola Censuaria") provides data on ownership and on qualitative/quantitative parameters related to Real Estate Unit .
Information about Real Estate Units (REU) contained in the Cadastral Census Table are the core of the cadastral informative heritage: from these data it is possible to obtain information about each property, with the possibility to generalize information at building level. For instance, the position of each dwelling within an apartment block allow to determine the total number of floors below and above the ground of the building itself. Moreover, REU data might be spatialized through the connection with the cadastral map: each real estate unit registered is provided with a code that allow to identify the parcel on the map where the real estate unit is located.

A first critical point of the cadaster is related to the incompleteness of available information. The cadaster is the 
reference database for all real estate nationwide: its archives are completely on digital support by now and its update is constant as it is part of the administrative procedures related to the construction sector, in case of refurbishments or new constructions. Data fluxes are structured and based on dedicated software (PREGEO and DOCFA). Nevertheless information contained in the cadaster are not always complete: the digitization process started at the end of 80 s and the update mechanism introduced determined the availability of new data in case of refurbishment or new constructions, omitting an extensive update on data concerning buildings that do not undergo renovations; furthermore, completeness and compliancy controls on the quality of data are not based on software or any other form of automatic testing.

Another critical issue concerns the cadastral map and the possibility to spatially relate the cadastral map with other spatial datasets, especially the TDB. The cadastral map is the georeferenced component of the land registry and it is realized in the historical National Coordinate System "Roma Monte Mario". Nevertheless this geographic layer is not directly interoperable with the TDB geometries: these two cartography, realized in different times, with different methods (airborne photogrammetry for the TDBs and topographic survey for the cadastral map) and with different purposes are currently misaligned.

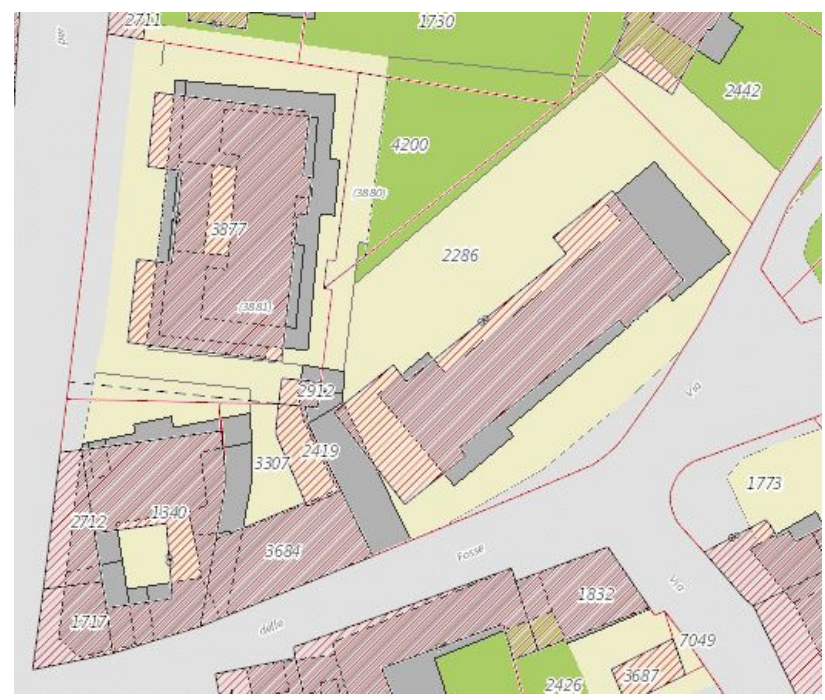

Figure 2. Misalignment between buildings in TDB and buildings in the cadastral map

Moreover, the cadastral map is not used as a background layer during the production of TDB and geometric consistency between buildings in the TDB and building in the cadastral map has to carried out in post-production phase. This is a timeconsuming process that requires cadastral map to be aligned (and sometimes re-drawn) on the TDB and buildings geometries (in the TDB) eventually re-defined following parcel boundaries. Nevertheless this association is the premise not only for the connection with cadastral information, but also with further datasets on buildings that refer to cadastral identifiers: this is the case of CENED database on Energy Performance Certification, containing relevant information on those aspects of real estates that influence their energy performances; also the CURIT database concerning thermal plants is directly connected to cadaster.

\subsection{Census data}

Since 2001 the National Institute of Statistics (ISTAT) has undertaken the survey of information about buildings in occasion of the national census on population and houses that take place every 10 years.

For what concerns the census of buildings, a specific form was set up for the collection of data in order to describe the features that characterize the national building stock. Data collected refers to:

- address;

- the position of each building with respect to others (detached building or building complex, adjacent or separate),

- functions hosted;

- year of construction;

- number of floors under and above the ground;

- existence of elevators;

- number of stairs;

- condition of the construction (used or disused, level of maintenance).

These parameters might be coupled with other information that are collected through the form used for the census of people and houses: in this second form specific data on single residences are reported, concerning the size and the number of rooms, qualitative information on plants (hot water and heating), the availability of renewable energy source, etcetera. The address reported at the bottom of both these two forms work as key data to relate information referred to an entire building and the single residences located inside. Furthermore the location of buildings provided through the address enable the spatialization of census data.

Censed data are connected to a national address database created during last census session in 2011. This database is currently being shared with and adopted by local authorities: national and local addresses databases are so progressively aligning. An agreement were also reached between the National Institute of Statistics and the National Tax Agency for the shared adoption of the new addresses: databases which are under the sphere of competence of the Tax Agency will be soon connected to the national addresses database. Beyond official registers, the address is a key reference for most of information concerning citizens (building users): thus the geo-referencing of addresses opens up the possibility to investigate the relations between users behaviors, needs and preferences and urban spaces.

\section{THE CREATION OF A LOCAL BUILDING INFORMATION SYSTEM}

As previously stated, an efficient territorial management relies on information: for what concerns the built environment, geographic data play a significant role in the creation of an integrated information system on buildings that can support administrative activities and the provision of new form of services. The analysis proposed in section 2 revealed how, in foreign countries, the systematization, harmonization and interconnection of key archives, including also building-related databases, was part of a national strategy that aimed to improve efficiency in administrative management. In Italy, this general review of the public information system still lack and the role of geographic information is taking a long time to emerge. From this point of view a real data integration strategy is currently 
missing and also TDB cartographies are still conceived as pure mapping tools. Nevertheless, at local level different degree of familiarity with such themes can be detected: in order to overcome the inertia at national level, a bottom up approach can be followed since every local administration can access public registries (cadastral and census data included) in the same way through the so called "Public Connectivity Service".

The objective of the research project is to create a Building Information System, a city-wide informative hub related to the built assets, aimed to combine together the set of available information concerning buildings. Starting from an analysis of available data bases, it is possible to define a set of rules and procedures in order to create a smart information system on buildings: this would enable the implementation of such system by each interested administration. In doing so, it is crucial to define standardized and replicable rules for the interrelation between data, in order to enable public administrations to repeat the whole process.

The cornerstone of such process is the geographic information, and the Topographic Database (TDB) in particular, for two reasons: firstly because each building, as "unmovable asset", occupy a specific position in the space and the relationships of each building with the surrounding environment are relevant for the building itself; secondly because from the TDB it is possible to derive 3D geometric contents for all buildings within a city. The idea is to use the buildings contents coming from the topographic database as the core of the building information system: this would enable to exploit advantages related to a georeferenced information and the possibility to carry out spatial analysis also considering other spatial databases on phenomena that might impact on buildings (like risk zone maps). The data model considered is CityGML, in line with the European requirements.

From a geometric point of view, considering its positional and height accuracy, the TDB is a suitable base for the creation of city models "in between" among the LOD1 and LOD2, according to the international standard CityGML. Accuracy of the TDB in urban areas ranges as follow:

- $0,60 \mathrm{~m}$ positional and height accuracy in zones mapped with a 1:1000 scale;

- $1,2 \mathrm{~m}$ positional and $0,80 \mathrm{~m}$ height accuracy in zones mapped with a 1:2000 scale;

Thus the most of existing TDB (available at 1:2000 scale) is fully suitable for the creation of a LoD1 city model and slightly exceed accuracy requirement for a LoD2: at the same time the modelling of roof surfaces is generally missing.

From a semantic point of view, basic attributes required by the CityGML Core Profile, like the year of construction or the number of floor below the ground, are not included in current TDB and have to be retrieved in other databases. The integration between TDB and external databases have to be operated in post-production phase and involve a long harmonization process aimed to properly relate data (e.g. building in TDB with the correct cadastral references and address). Nevertheless this effort would contribute to align the quality of Italian information on buildings to international and European standards.

Of course this is quite a time-consuming process and in order to provide sound arguments supporting this work the usability of such integrated information have to be tested and validated in practical use cases. The final scope of this usability testing is to state with which accuracy it is possible to carry out analysis on the whole building stock within a city or a district once data integration is completed.

\subsection{Use cases}

The quality and usability of the Information System obtained have to be evaluated. For this purposes, some use cases concerning analysis on built assets will be tested and the outputs will be validated in order to measure the degree of error of analysis based on the integrated data on buildings.

To this purpose, energy estimates at city scale seem to be an interesting field of application: in its work, Agugiaro (2014) describes the attempt realize energy audits for a neighborhood of the city of Trento, creating a 3D city model starting from building footprints and LIDAR data for the modeling of geometries and integrating semantic information extracted from the cadaster. Instead of LIDAR data, TDB building geometries, obtained through airborne photogrammetric survey and soon available for every municipality in Italy, might the optimal candidate to be the geometric base for the realization of a city model aimed to support energy analysis: this would enable the computation of a fine grain energy requirement estimate, automatically analyzing all buildings within a neighborhood or a city. It is due to highlight that electric and gas consumption data are currently collected by the Tax Agency with an annual frequency and sent to the municipalities for fiscal checks: hence, a confrontation with real consumption data will allow a validation of the results, identifying the range of error that might be encountered and defining whether the accuracy obtained is sufficient or not. In turn outputs coming from citywide energy analysis may become a supplementary information of the Building Information System, and made available to the public: this might also be an effective way for local administrator to share, report and discuss the results of their decisions with the citizens and the community. A clear example, in this sense is provided by the Energy Atlas of Berlin (Kruger and Kolbe, 2012).

Moreover, also the field of environmental risks may benefit from a fine grain database on building features: in fact, the impact of a catastrophic event is determined not only by the magnitude and the extent of a flood or an earthquake, but is also connected to the characteristics of the building shock. Developed countries, where anthropic settlements determined extensive urbanization processes, have to deal with an existing building stock located in hazard prone areas which is not always «hazards proofed» and is ageing: such built assets require the implementation of mitigation and protection measures against natural threads that are continuously evolving due to the current global climate change. Several references provide lists of parameters to be considered in the evaluation of vulnerability (Federal Emergency Management Agency, 2007) (Van Westen et al. 2008) (Zlatanova et al., 2014) and fine grain analysis on buildings vulnerability are not new in the scientific panorama (Sucuoğlu et al., 2007) (Ernst et al., 2010) (Stephenson et al., 2014).

The resort to city models for the generation of physical vulnerability assessment of buildings would allow to have a massive pre-audit on all buildings in a city, allowing to highlight how each single building might respond to natural stressors depending on the features that characterize it. For example, the procedure defined in (Meroni et al., 2000) and adopted by the National Institute of Geophisic and Volcanology 
(INGV) for the determination of buildings vulnerability to seismic risk is based on the parameters collected every ten years by the National census. Up to now, estimates are referred to municipalities as the National Institute of Statistics used to provide data at municipal scale: thus it is possible to determine in which municipalities a higher annual loss rate is expected on the global building stock. Now, as ISTAT collect data using the house numbers as a spatial reference, it would be possible to automatically transfer such parameters on a city model and to automatically compute the analysis for all buildings, making distinctions between more and less vulnerable constructions.

\section{CONCLUSIONS}

The research project aims to gather all available and relevant data for all buildings within a city: the results will be a "readyto-use" package of information that might be used for the development of applications and in the realization of analysis at city scale. This will open the possibility for public administrator to improve efficiency in administrative duties and to increase the quality of services provided to the citizens. This integrated information will also ease sectorial, fine-grain analysis on buildings that will orient public policies and will highlight new possibilities in constructions market.

The experience connected to the "National GIS agreement" in Italy had an important role in the spread of geographic information, but more work is required in terms of real use and usability of geo-data: as at national level the discussion on further development is now at a stalemate, the possibility to relaunch the debate might come from virtuous local realities.

Due to the digitalization process that is taking place not only in the construction sector, but within the society new data sources arose, storing huge amount of data that contribute to enrich and improve the informative quality of traditional/official datasets. The connection with these new data sources (data from Building Information Models, data from sensors, crowdsourced data) is strategic in order to overcome current criticalities related to the incompleteness and out-of-dateness of official datasets and also to enrich existing contents, making the quality of Italian geo-information suitable for smart applications.

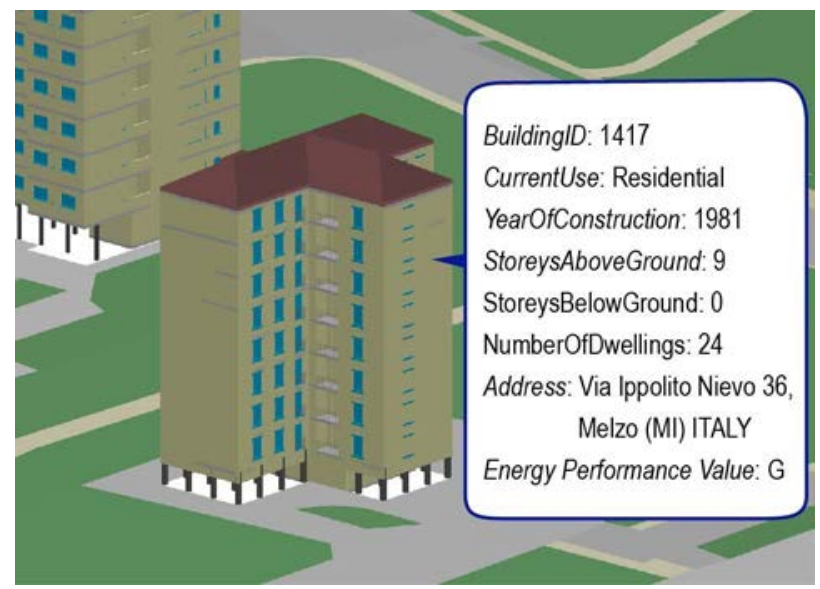

Figure 3. Geometric and semantic enrichment of building data through the integration different datasources (TDB, cadastral data, BIM data). Image by Alice Pasquinelli and Daniela Pasini.

\section{ACKNOWLEDGEMENTS}

The analysis proposed in this paper is part of a Ph.D. research project co-financed by Comunità Montana Valle Sabbia and the ABC Department of Politecnico di Milano. The authors wish to thank Eng. Daniela Pasini for her substantial support in testing the use of BIM data for the enrichment of geometric TDB contents.

\section{REFERENCES}

Association for Geographic Information, 2015. AGI Foresight 2020

Agugiaro, G., 2014. I modelli digitali 3D di città come hub informativo per simulazioni energetiche a scala urbana, Atti della 18a Conferenza Nazionale ASITA, Firenze 14-16 ottobre 2014

Kruger, A., Kolbe, T. H., 2012. Building analysis for urban energy planning using key indicators on virtual 3d city models The energy atlas of Berlin, International Archives of the Photogrammetry, Remote Sensing and Spatial Information Sciences, Volume XXXIX-B2

Bakker, N. J., van der Vegt, H. H., Bruns, B. 2013. Dutch NMCA launches Open data. Proceedings of the 26th International Cartographic Conference, August 25-30, 2013, Dresden, Germany

Bignami, D. F., 2010. Protezione Civile e riduzione del rischio disastri. Metodi e strumenti di governo della sicurezza territoriale e ambientale, Santarcangelo di Romagna: Maggioli Editore

Billen, R., Cutting-Decelle, A.F., Métral, C., Falquet, G., Zlatanova S. and Marina, O., 2015. Challenges of semantic 3D city models: a contribution of the COST Research Action TU0801, International Journal of 3-D Information Modeling, Volume 4 Issue 2, April 2015

Biljecki, F., Stoter, J., Ledoux, H., Zlatanova, S. and Çöltekin, A., 2015. Applications of 3D City Models: State of the Art Review, ISPRS International Journal of Geo-Information, 4, pp. 2842-2889

Conejo Fernández, C., 2003. Spanish Cadastral Information System: Current status and I.T. Renovation Strategy, Revista CT/ Catastro Nro 48. Julio 2003

Directive 2010/31/EU of the European Parliament and of the Council of 19 may 2010 on the energy performance of buildings (recast). Official Journal of the European Union.

Directive 2012/27/EU of the European Parliament and of the Council of 25 October 2012 on energy efficiency. Official Journal of the European Union.

Directive 2007/2/EC of the European Parliament and of the Council of 14 March 2007 establishing an Infrastructure for Spatial Information in the European Community (INSPIRE)

European Parliament, Directive 2007/2/EC establishing an Infrastructure for Spatial Information in the European Community (INSPIRE) 
Ernst, J. et al., 2010. Micro-scale flood risk analysis based on detailed 2D hydraulic modelling and high resolution geographic data. Natural Hazards, 55(2), pp.181-209.

Federal Emergency Management Agency (Homeland Security Department), 2007. National Flood Insurance Program (NFIP), Complete Library of FEMA Documents, Homeowner and Builder Guides, Floodplains, Mapping, Agent Information, Mitigation, Manuals, Progressive Management 2007

Hawerk, W. 2001. ALKIS - Germany's Way Into A Cadastre For The 21st Century, FIG Working Week 2001

IEA-EBC Annex 51 Energy Efficient Communities: Case Studies and Strategic Guidelines for Urban Decision Makers 2013

INTESA GIS - Comitato tecnico di coordinamento, 2008 Specifiche per la realizzazione dei data base topografici di interesse generale

INSPIRE - Infrastructure for Spatial Information in Europe, 2014. Data Specification on Cadastral Parcels - Technical Guidelines (D2.8.I.6_v3.0.1)

INSPIRE - Infrastructure for Spatial Information in Europe, 2013. Data Specification on Buildings - Technical Guidelines (D2.8.III.2_v3.0)

Isikdag, U., Horhammer, M., Zlatanova, S., Kathmann, R., van Oosterom, P., 2014. Semantically rich 3D building and cadastral models for valuation, Proceedings 4th International Workshop on 3D Cadastres, 9-11 November 2014, Dubai, United Arab Emirates

Mair, R., 2015. How will city infrastructure and sensors be made smart?, Essay commissioned as part of the UK government's Foresight Future of Cities project.

Menoni, S., Molinari, D., Parker, D., Ballio, F., Tapsell S. 2012. Assessing Multifaceted vulnerability and resilience in order to design risk-mitigation strategies, Natural Hazards, Volume 64, Issue 3 , pp 2057-2082

Meroni, F., Petrini, V., Zonno, G. (2000), Distribuzione nazionale della vulnerabilità media comunale, in A. Bernardini (a cura di), La vulnerabilità degli edifici: valutazione a scala nazionale della vulnerabilità sismica degli edifici ordinari, CNR - Gruppo nazionale per la difesa dai terremoti, Roma, 2000

Nouvel, R., Zirak, M., Dastageeri, H., Coors, V. and Eicker, U., 2014, Urban energy analysis based on 3D city model for national scale applications, 5th German-Austrian IBPSA Conference, pp.83-90.

Olivares García, J. M., Virgós Soriano, L. I.and Velasco Martín-Varés, A., 2011. 3D Modeling and Representation of the Spanish Cadastral Cartography, 2nd International Workshop on 3D Cadastres 16-18 November 2011, Delft, the Netherlands

Open Geospatial Consortium, 2012. OGC City Geography Markup Language (CityGML) En-coding Standard, OGC 12019, Version: 2.0.0
Stephenson, V. \& D’Ayala, D., 2014. A new approach to flood vulnerability assessment for historic buildings in England. Natural Hazards and Earth System Sciences, 14(5), pp.10351048.

Strzalka, A., Bogdahn, J. and Eicker, U. 2010. 3D City Modelling for Urban Scale Heating Energy Demand Forecasting. Ashrae Hvac\&R, 17(4), pp.526-539.

Sucuoğlu, H., Yazgan, U. \& Yakut, A., 2007. A screening procedure for seismic risk assessment in urban building stocks. Earthquake Spectra, 23(2), pp.441-458.

United Nations Committee of Experts on Global Geospatial Information Management (UN-GGIM), 2015. Future Trends in geospatial information management: the five to ten year vision Second Edition, August 2015

Van der Molen, P., 2002. Partnerships for better service PublicPrivate and Public-Public Partnerships to achieve better service to customers in the Netherlands.

Van Westen, C.J., Castellanos, E. \& Kuriakose, S.L., 2008. Spatial data for landslide susceptibility, hazard, and vulnerability assessment: An overview. Engineering Geology, 102(3-4), pp.112-131.

De Zeeuw, K. and Salzmann, M., 2011. Cadastral Innovation Driven by Society: Evolution or Revolution?, FIG Working Week 2011 Bridging the Gap between Cultures Marrakech, Morocco, 18-22 May 2011

Zlatanova, S., Ghawana, T., Kaur, A., Neuvel, J. M. M., 2014, Integrated flood disaster management and spatial information: case studies of Netherlands and India, The International Archives of the Photogrammetry, Remote Sensing and Spatial Information Sciences, Volume XL-8, 2014

\section{Websites}

www.adv-online.de/

http://inspire.ec.europa.eu/

www.kadaster.nl

www.istat.it

www.ordnancesurvey.co.uk

www.intesagis.it

www.regione.lombardia.it 